\title{
Comparative Ameliorants Efficiency of the Spring Barley Productivity Grown in Sodium -Sulphate Saline-Alkali Soil (Solonchak-Solonets) Conditions
}

\author{
Kanaibek Kubenkulov, Nurzhamal Khokhanbayeva, Askhat Naushabayev, Roza Assylova, \\ Kerimbek Zhumadilkhan ${ }^{1}$ \\ ${ }^{1}$ Kazakh National Agrarian University, Almaty, Kazakhstan
}

\begin{abstract}
In the article are considered the matters of reclamation efficiency of elemental sulfur with various dispersion in the soda-saline soils of the plain of the southeast of Kazakhstan.
\end{abstract}

Keywords: brackish soil, alkalinity, sulfur, dispersion, reclamation.

\section{Introduction}

The irrigation farming zone located on the piedmont plains of the Northern Tien Shan is characterized by a sharp climate aridity, insufficiency and instability of atmospheric precipitation, the presence of significant arable land areas with a low level of natural fertility of soils due to their salinity and alkalinity. Among the measures aimed at increasing the productivity of agricultural crops and the sustainability of farming, the main thing is the reclamation of saline lands. Insufficient study of reclamation measures on irrigated alkaline saline soils, required conducting real research on establishing comparative ameliorative efficiency of phosphogypsum, elemental sulphur, sulphuric acid on sodium-saline soils. In this regard, we have studied the effect of the above-mentioned ameliorants on the productivity of spring barley [1-2].

\section{Materials and Methods}

The solution of the set tasks was carried out by setting field experiments using calculated dose equivalent of ameliorants under the conditions of spring barley cultivation by a sprinkler irrigation system. The studies were held in 2015 and 2016 in the territories of Amiran LLP in Talgar district of Almaty region. The soil of the experimental site is represented by sodium-saline soil, located in the form of a spot, with area of 1.7 hectares, among non-saline meadow light sierozem.

The schedule of the field experiment
1. Control
Without ameliorants
2. Phosphogypsum
$43.1 \mathrm{~kg}$ for a plot or $27 \mathrm{t} / \mathrm{ha}$
3. Elemental sulphur
$8.3 \mathrm{~kg}$ for a plot or $5 \mathrm{t} / \mathrm{ha}$
4. Sulphuric acid
$24.9 \mathrm{~kg}$ for a plot or $15.4 \mathrm{t} / \mathrm{ha}$

The plot area is $15 \mathrm{~m}^{2}$, the replicate is 3-fold. The doses of ameliorants are calculated to a depth of 0-50 cm according to the formula of B.M. Agayev (1966). Ameliorants were introduced on November 25, 2015. Sowing of spring barley was carried out on April 19, 2016. Sampling of soils was carried out before the introduction of ameliorants and the main phases of barley development (boot and full ripeness phase) from a depth of 0-20 and 20-40 cm. The water extract ions composition was determined. Phenological observations of biometric measurements were carried out according to the generally accepted method. The harvest was recorded in a five- 
fold replicate. Data on the influence of ameliorants on the growth of experimental plants are presented in Table 1.

TABLE I. Ameliorants Influence on the heights of spring barley plants

\begin{tabular}{|l|l|l|l|}
\hline \multirow{2}{*}{ Variant } & \multicolumn{3}{|c|}{ Height of plants, cm } \\
\cline { 2 - 4 } Control & boot & ear & full ripeness \\
\hline Phosphogypsum & 31.1 & 76.7 & 78.5 \\
\hline Elemental sulphur & 33.7 & 81.6 & 83.3 \\
\hline Sulphuric acid & 34.6 & 82.6 & 84.6 \\
\hline
\end{tabular}

\section{Results and discussion}

The results of the biometric measurements of spring barley plants in the booting phase show noticeable differences between the plant variants of the experiment in plant height. In this case, the plants with sulphuric acid differed in height with the highest height $(37.6 \mathrm{~cm})$, exceeding the plant of control variant by $6.5 \mathrm{~cm}$. The height of the plants in the variants with phosphogypsum was $34 \mathrm{~cm}$, which was 2.5 to $3.0 \mathrm{~cm}$ higher than the plants of the control variant

The regularities observed in the growth of spring barley in the booting phase are also observed in subsequent phases of development, retaining the same values of the difference in height between the variants of the experiment. It should be noted that the maximum height of barley plants in the phase of full ripeness $(85.1 \mathrm{~cm})$ observed in the sulphuric acid variant was the same as in non-saline meadow light sierozem, which spread around the experimental site. This indicates a high melting efficiency of sulpuric acid, which allows to increase the level of effective fertility of sodium-sulfate saline-alkali (solonchak-solonets) soils up to the level of zonal soil non-saline meadow light sierozem [3].

The study of the water extracts composition of soils showed a significant change in the qualitative indicators of soils by ameliorants, as a result of which the initial sodium-sulphate solonchak was transformed into slightly saline soil with sulphate chemistry in the variant with sulphuric acid and in medium and strong salinity soil in the variant with sulphur. The reason for this is not a decrease in the total content of salts, but a change in composition of salts, namely a decrease in the proportion of high toxic salts [4]. As a result, the changes in the salt composition of the tested soils, as their integral reflection, are manifested in the $\mathrm{pH}$ values, reducing its value in the plowing soil to 8.2 on the variant with sulphur and 8.1 sulphuric acid, at 8.4 at the control. The various soil conditions created by ameliorants, which led to differentiation in the spring barley growth, ultimately led to the formation of different levels of grain yields (Table 2).

TABLE II. The effect of phosphogypsum, elemental sulphur and sulphuric acid calculated dose equivalents on the spring barley yield cultivated on the sodium-sulphate saline-alkali soil of light sierozem subzone under the sprinkler irrigation system conditions

\begin{tabular}{|c|c|c|c|c|c|c|}
\hline \multirow{3}{*}{ Variant } & \multicolumn{4}{|c|}{ Grain yeild, c/ha } & \multicolumn{2}{|c|}{ Increase } \\
\hline & \multicolumn{3}{|c|}{ Replicate } & \multirow[t]{2}{*}{ Average } & \multirow[t]{2}{*}{$\mathrm{c} / \mathrm{ha}$} & \multirow[t]{2}{*}{$\%$} \\
\hline & $\mathrm{I}$ & II & III & & & \\
\hline Control & 20.91 & 21.44 & 17.24 & 18.90 & - & - \\
\hline Phosphogypsum & 24.01 & 27.01 & 19.61 & 21.44 & 2.54 & 13.4 \\
\hline Elemental sulphur & 27.72 & 29.97 & 26.30 & 27.01 & 8.11 & 42.9 \\
\hline Sulphuric acid & 30.13 & 21.23 & 30.55 & 29.97 & 11.07 & 58.6 \\
\hline
\end{tabular}

It should be noted that barley, as a medium salt tolerant crop, despite severe soil conditions, due to the fall of record abundant spring precipitation and the creation of optimal moisture regimes in the phases of intensive accumulation of overground mass by sprinkler irrigation, formed a moderate level of grain yield (18.90 c/ha). Against the backdrop of such climatic and agrotechnical conditions, the introduction of phosphogypsum notedly improving the soil conditions contributed to the increase in the yield of barley grain by $2.5 \mathrm{c} / \mathrm{ha}$ or $13.4 \%$ compared to the control. As expected, the maximum yield of barley grain $(29.97 \mathrm{c} / \mathrm{ha})$ was obtained on a variant with sulphuric acid. Close to it barley yield was obtained on a variant with elemental sulphur (27.01 c/ha). The 
grain yield on non-saline soil was $32.5 \mathrm{c} / \mathrm{ha}$. In general, the obtained gains in barley grain yield fully correspond to the changes manifested in the growth of barley plants and soil conditions created from the types of introduced ameliorants.

\section{Conclusion}

As such, the results of conducted field experiments to establish the comparative effectiveness of equivalent doses of ameliorants showed high efficiency of sulphuric acid in comparison with the others. It is recommended to use sulphuric acid, and in case of its absence, elemental sulphur for reclamation of sodium-saline soils.

\section{References}

[1] Borovski V.M. Geochemical salinize soil of the Kazakhstan, Science, Moscow, 1978, 172p.

[2] R.S. Bespaev, "Melioration Meadow-serozem soils mountain of Ily Alatau", synopsis candidate Agriculture Science, Uzbekistan, Tashkent, 1988, 17p.

[3] I.I. Feofarova, "Psevmorvous calcite by gypsum in the soils", Proceedings of the Soil Institute of the after name of V.Dokuchaev, ch. 34, 1950, pp.202-206.

[4] Contour of the technological development oil gas factory direction in the Kazakhstan. Fase 2. Analyses technological complication. prepare: department project and technology factory Shell, December, 2011, pp.44-47. 